\title{
Examining the Appropriateness of Reiss's Functionalist-oriented Approach to Trancism
}

\author{
Hamidreza Abdi \\ Freelance Researcher, Iran
}

\begin{abstract}
Trancism is an activity that is put into Holmes' (1972) applied branch of Translation Studies (TS). The aim of trancism is to make a fair judgment to help improve the translation through the constructive comments provided by the critic. Various approaches have been proposed to achieve an objective judgment in order to avoid making a subjective judgment. The present study investigated the appropriateness of Reiss's (2000) approach to the critique of a translation. To do end, the English version of Rowling's (2000) Harry Potter and the Goblet of Fire and its Persian translation were chosen as the corpus of the present study to evaluate the Persian translation on the basis of three categories included in Reiss's model of trancism. This encompasses literary, language, and pragmatic categories. As the results indicated, the translator was successful in accomplishing her translation at almost all levels, except some part of grammatical and punctuation included in language category in which the translation she produced resulted in failure to some extent. In conclusion, Reiss's functionalist approach was mostly appropriate to the critique of a translated text, especially expressive text types, because her model allows the critic to judge two main aspect of the translation: linguistic and extra-linguistic aspects.
\end{abstract}

Index Terms - trancism, corpus-based translation studies (CTS), functionalist approach

\section{INTRODUCTION}

Translation Studies (TS) is a complex concept because it is made up of a set of disciplines, such as comparative literature, linguistics, philosophy, and so on., and deals with all aspects of the translation systematically, namely linguistic and cultural aspects. TS is divided into two categories: theories and practices. The former makes us familiar with different types of theories proposed to study various aspects of the translation; whereas the latter teaches us how to make good use of such theories in practice. According to Holmes (1972), translation practices/ applied branch of TS is put into three sub-categories, including translator training, translation aids, and translation criticism; of which the latter was the focus of the present study.

Trancism, the term has been coined by the researcher for Translation Criticism, used to assess translations. Kreiner (2006) states that trancism is frequently conducted by making a comparison between source and target texts. In cases that the ST is not available, it, as she implies, is common to criticize the TT because people whose mother tongue is the language of translation occasionally can recognize awkward phrasing of translations. For Toury (2012), culture plays the main role in trancism because of that the critique of a translation encompassing a careful analysis of the metatexts made in accordance with a given culture.

Holmes (1970) believes that undoubtedly, the activities relating to translation interpretation and evaluation are always mainly far removed from the understanding objective analysis, and therefore reflect the intuitive, critical impressionist attitudes and positions. That is to say, the systematic method is rarely used to analyze translations and the analysis restricted to personal bias. Thus, one characteristic of translation analysis "is indeed the lack of value judgement" (Hewson, 2011, p. 5). This may be due to the misconception we have about the critique of a translated text. In a sense, most reviewers pay more attention to the negative aspects of a translation and do not consider the positive aspects when criticizing a translation. Thus, this image may arise that they intended to make the translation worthless, not help improve it.

Reiss (2000) discusses that the reason of such unfair judgments is that reviewers do not invest enough time and effort to make a comparison between a translation and its source language (SL), even if the language is familiar to them. She further states that it will mostly happen if the SL is either English or French, rarely if it is the language other than European language, and very infrequently if it is any other language. It implies that this is the reviewer who is responsible for improving the quality of the translation by providing his/her valuable comments on it.

In order to achieve a constructive evaluation, the objective judgment needs to be made instead of the subjective judgment. Valero (1995) expresses that the objective of the critic needs to be clear and some parameters must be observed. These parameters, as she clarifies, are "to explore the type of scientific frame of reference and to establish a general model of analysis" (p. 203). In this regard, Reiss (2000) mentions that the translation "should be evaluated by objective and relevant criteria" (p. 4). Thus, making a comparison between the ST and TT, as Reiss emphasizes, is a need for trancism and the translator's work must be characterized. 
In the light of Reiss's (2000) approach to trancism, the present study aimed to make a comparison between the English version of Rowling's Harry Potter and the Goblet of Fire and its Persian translation to find whether Reiss's approach is appropriate for the judgment of the translation. To achieve the objective of the present study the following question was raised:

To what extent Reiss's (2000) approach is appropriate for trancism?

It is hoped that the findings of the present study help improve the quality of the Persian translation under investigation and other works that are supposed to be conducted by the translator in the future. Furthermore, the results of this study should be beneficial to those who have an interest in this sub-field of TS, and to those who started their career as critics.

\section{REVIEW OF THE RELATED LITERATURE}

\section{A. Trancism from Different Approach}

Trancism, in Hewson's (2011) approach, "involves an interpretative act whereby the basis of the value judgement is explicitly spelled out" (p. 6). According to him, trancism aims to give details of the potential judgment of a translation that is seen under an established interpretative framework originated in the ST. Hewson states that such a critique is far beyond implicit judgements and other approaches search through the translation to highlight its weaknesses. He declares that trancism is "evaluative," because it investigates a potential judgment of the translation and also seeks the extent to which the translation is similar to or different from the ST's potential judgment that is perceived.

For Newmark (1988), trancism is "an essential link between translation theory and its practice" (p. 184). He also considers it informative and pleasurable activity. The evaluation of two or more translations of the ST, as Newmark explains, allows us to become familiar with various translation styles, and be aware of that there can be different translations of a text, depending on what translation method the translator employed. The challenge arises when the reviewer states his own principles unquestionably when criticizing. But it is necessary to clarify the translator's principles as well. New mark believes that in order to achieve a good trancism, the reviewer should provide a summary of the ST analysis, the interpretation the translator expressed about the ST, and the translation method he applied. He also needs to give a representative detail of the comparison made between the ST and TT as well as a judgment of the translation from both the translator's point of view and his own view. In addition, making an evaluation of the likely place where the translation was produced in the TL culture.

Rainer Schulte (2019), who is known as a translator, poet, playwright, essayist, and critic of contemporary international literature, implies that trancism needs to be conducted by the one who is able to recognize the SL, the cultural and aesthetic context of the ST, and the linguistic differences between the SL and TL. According to him, reviewers are to some extent unwilling to provide their comments on the nature of a translation. Schulte further states that such reviewers are not even aware of that they are supposed to review a translation and cause the translation to get better. This is due to that, as he justifies, a very small number of critics are translators themselves. Schulte describes that a good criticism obtained when the translator himself, as the best-qualified person, carries out the critique of a translation; but, this will never happen due to that translators prefer to invest most of their time on the act of translation rather than criticism.

\section{B. Reiss's Approach towards Trancism}

In her book Translation Criticism-The Potentials and Limitations: Categories and Criteria for Translation Quality Assessment, Reiss (2000) proposes three categories, including literary, language, and pragmatic categories, required to objectively criticize a translated work. Literary category, as she states, pays special attention to text types. That is to say, the first step is to determine the text type under evaluation and identify the appropriate translation strategy the translator employed to translate the text, and then to assess the extent to which the translator fulfil the relevant criteria.

Reiss (2000) clarifies that if the text is a focused-content, the primary concern is the accuracy of data.; if it is $a$ formfocused, the accuracy of information needs to be paid careful attention; if it is an appeal-focused, the achievement of intended purpose of the ST should be considered; and if it is an audio-medial text, the accommodation of the relevant media and the incorporation of their contributions need to be concentrated.

Language category, as Reiss (2000) discusses, refers to "linguistic features and their equivalents in the TL" (p. 48). It implies a detailed investigation of the representation of linguistic peculiarities of the SL in the TL as she states. In this way, four components of a text should be taken into account, namely semantic, lexical, grammatical, and stylistic components, of which the first component is "a critical factor in preserving the content and meaning of the original text" (p. 53). To achieve the best semantic equivalence, Reiss recommends examining the linguistic context where the author's intention is obviously seen by what is said.

Reiss (2000) considers adequacy the standard for the lexical components. The reason given by her is that because word for word translation, which most often demanded as a general strategy in the TL, cannot be effective as an objective criterion because of that the vocabularies relating to any language-pair simply cannot be completely similar. Thus, determining the adequate transfer of the ST's components to the TL on the lexical level, as she points to, is a need for the critic to take into account. Reiss mentions that correctness is a valid criterion for the judgment of the translation in connection with the grammatical components of a source text because there is a great difference between the 
grammatical systems of two languages. She makes clear that grammatical correctness is achievable when the translation complies with usage of the TL and when the suitable semantic and stylistic features of the grammatical structure of the SL have been perceived and adequately translated.

The complete correspondence between the ST and TT, as Reiss (2000) implies, is a key factor that must be given careful consideration by the critic when evaluating the stylistic component. In other words, the critic, as she argues, needs to look carefully at the translation to see whether it encompasses standard, individual or contemporary usage relating to stylistic components of the ST. She emphasizes that considering this component is of great importance when evaluating the translation of form-focused and appeal-focused texts. Pragmatic category which is focused on extralinguistic determinates is the last category that the critic should consider it carefully, alongside the two previous categories, to make an objective judgment.

The extra-linguistic determinates relating to the ST and TT play the important role in achieving a good judgment just as much as the linguistic elements do. The extra-linguistic determinants contain a variety of factors. This includes the immediate situation, the subject matter, the time factor, the place factor, the audience factor, the speaker factor and affective implications. These factors provide the author with the opportunity to make the best choice from available methods in his mother tongue which would be understandable to the reader or hearer, and also enable him "to ignore certain linguistic means and still be understood by members of his language group" (p. 67).

\section{METHOD}

\section{A. Corpus}

The corpus of the present study consists of the English version of Rowling's Harry Potter and the Goblet of Fire, the fourth novel in the Harry Potter series, published by Scholastic Press in the United State on 8 July 2000 in 755 pages, and its Persian translation that was made by Vida Eslamieh (2002) and published by Tandis Publication in 414 pages. It should be noted that the Persian translation of Rowling's Harry Potter and the Goblet of Fire was published in two volumes. The first volume included 20 chapters, and the second 17 that this study focused on 10 chapters of the first volume.

J. K. Rowling, a pen name for Joanne Rowling, is a British author and philanthropist. Her famed is for her creative writings of the Harry Potter fantasy book series that caused her to win multiple awards and sold more than 500 million copies. Vida Eslamieh was born in 1967. She graduated in Translation Studies from Azad University. She has been translating since 1991. She began her first translations with Agatha Christie's stories. She worked as an editor for a time, until she began translating Harry Potter book series. She is also an Iranian translator famed for her translations of the Harry Potter book series.

The book is about what happens to Harry Potter, who is a wizard in his fourth year at Hogwarts School of Witchcraft and Wizardry, when he is forced to compete in the Triwizard Tournament. From available novels to the researcher, this novel was deemed to be appropriate to achieve the objective of the present study because not only was it the best-selling book series in history but also written by one of the famous English writers in the field. It also covered various references that posed serious challenges to the translator during the process of translation.

\section{B. Procedure}

Reiss's (2000) approach was applied to the analysis of the English version of Harry Potter and the Goblet of Fire and its Persian translation because she was a functionalist and his approach was a practice-oriented model lain under Holmes's applied branch of TS. To do this, the 10 out of 37 chapters of the novel and their translations into Persian were carefully analyzed to examine the appropriateness of Reiss's trancism approach within the context of the findings via given examples. The translation of the novel was printed and released in two separate volumes of which the first included the translations of the twenty chapters of the original. The present study was a corpus-based Translation Studies (CTS), which was first proposed by Baker (1993). Hatim (1999) states that CTS offers a really new way of research that not only deals with what is in the TT but also with what is of the TT. This study also applied a qualitative analysis model. The model allows the researcher to provide a detailed analysis of the text on the basis of Reiss's three levels of trancism, including literary, language, and pragmatic levels.

\section{RESULTS AND DisCUSSION}

This section provides a detailed description of the appropriateness of Reiss's (2000) trancism approach. In this way, the chosen text Harry Potter and the Goblet of Fire and its Persian translation were analyzed on the basis of the three categories included in Reiss's approach to the critique of a translation. In the following, the results of each category alongside related examples are discussed.

\section{A. Literary Category}

Literary category defines the text type. In other words, this category enables the translator to decide what text type he wants to translate, and based on his selection, the translator choose the appropriate translation strategies for micro-level and an overall strategy for macro-level. This category, as Reiss (2000) implies, is the starting point for any judgment 
because the text type is determined. As the selected corpus Harry Potter and the Goblet of Fire is a novel, it is taken into account as an expressive text type. Such a text type, as Reiss argues, is form-focused and concerned with "how an author expresses himself' (p. 31).

\section{B. Language Category}

To assess the language category, the linguistic aspects of the text should be probed. This includes the semantic elements, the lexical elements, the grammatical elements and the stylistic elements. A discussion of these elements is provided as follows:

Semantic elements are of great importance because they deal with the content and meaning of the ST. Thus, the translator needs to do his best to provide the target readers with the TT to be understandable in terms of semantic by the exact transference of the meaning and content of the ST to the TT. In order to achieve the desired transference, the role the lexical elements play is highlighted to a great degree. This is because of that lexical elements refer to the adequate use of the ST's components in the TT. If the translator is not able to provide the TT with the lexical elements of the ST adequately, he does not accomplish his task at lexical level. This leads to his failure at semantic level of the translation. That is to say, these two elements are interrelated.

In the use of appropriate lexical equivalent, Eslamieh was not successful in some cases because she provided the ST word with two unrelated Persian equivalents (see example 1 and 2)

Example 1:

"The Little Hangleton all agreed that the old house was creepy." (p. 1)

Example 2:

"از نظر اهالى دهكده لينل هنكلتن اين خانه قديمى ترسناك و جندش آور بود." (ص. ( )

The story had been picked over so many times, and had been embroidered in so many places." (p. 1)

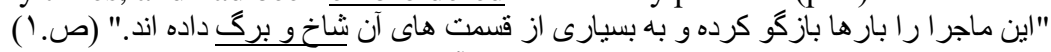

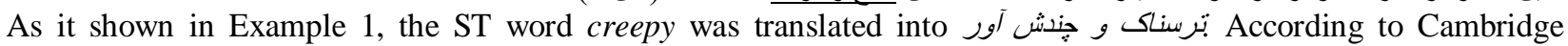
Advanced Learner's Dictionary, the word creepy means "strange or unnatural and making you feel frightened." This definition has nothing to do with the second Persian equivalent حنش آور given by the translator alongside the first Persian equivalent ترسناك refers to someone or something that is awfully unpleasant.

In Example 2, the ST word embroidered was correctly replaced by a Persian expression شاخخ و برك But, the problem is that such a translation is not considered a suitable one for all types of audiences. That is to say, the translator did not take into account all types of audiences. She should be aware of the audiences of this kind of novel, especially main audiences, before translating the text. The main audience of such a novel are teenagers who are mainly not able to understand these kinds of Persian expressions. As the results, the meaning of the above statement will may remain vague for them to some extent due to the incorrect transference of the meaning of it. To cope with, explanatory endnotes, footnotes, or any additional description could be used to make the Persian expression easily to understand to the audiences.

In some cases, the translator employed additional description to make the meaning of a word or phrase clear to the target readers that was successful in doing this (see example 3). The same strategy was employed by Eslamieh in cases that there were no the TT equivalent for the ST expression/word. Thus, the translator preferred to create the appropriate equivalent for such an ST expression/word instead of omitting it (Example 4). This helps enhance the target readers understanding not only of the ST item but also of the sentence/paragraph in which it is used. This implies the success of the translator at semantic level.

Example 3:

"Still in their dinner things!" (p. 2)

Example 4:

"Ton-Tongue Toffee, said Fred brightly." (p. 51)

"هنوز همون لباسهايى كه ديشب سرشام بوشيده بودن تنشونه!" (ص. ^)

"فرد باشوق و ذوق كفت: نافى زبون دراز كن بود." (ص. (\$)

As it is clear from Example 3, the ST phrase was replaced by a Persian sentence. This was because of that the meaning of the ST phrase was not fully understandable to the target reader. The translator correctly transferred the meaning and content of the ST phrase to the TT by adding extra descriptions. This helps the readers to have better understanding of the meaning of the ST phrase.

Grammatical elements deal with the correct use of grammatical structures and punctuations. As two different languages have two different linguistic systems, they will differ in terms of grammatical structures. For example, the basic grammatical structure in English is Subject + Verb + Object which is in contrast to the Persian grammatical structure Subject + Object + Verb. This grammatical structure has been observed by Eslamieh when translating the original novel into Persian (see Example 5).

Example 5:

"They had arrived on what appeared to be a deserted stretch of misty moor." (p. 75)

$$
\text { "آنها در يك صحر اى بى آب و علف وسيع و مه آلود فرود آمدند." (ص. }
$$


In grammatical level, the main problem that was not mostly observed by Eslamieh was punctuations, such as quotation marks, colons, dashes, and other marks (see Examples 6, 7, and 8). It should be noted that the researcher himself used quotation marks in all Persian examples, except Example 6 to show the problem.

Example 6:

"Yeah, I am," said Harry.

"But Dobby talks of you all the time, sir!" she said. (p. 98)

Example 7:

"Harry never knew whether or not he had actually dropped off to sleep — his fantasies of flying like Krum might well have slipped into actual dreams — all he knew..." (p. 118)

"هرى نفهميد كه به خواب رفته است يا نه. تصور اينكه روزى بتو اند به خوبى ويكتوركر ام برواز كند تبديل به روياى شيرين برواز شده بود كه

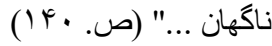

As Example 7 indicates, Eslamieh omitted the dash mark "-" and preferred to use full stop/period mark "."instead. It would be better observed the same grammatical rule because of that one usage of a dash mark is not only to insert pauses in a sentence/paragraph but also put emphasis on something written between them. The translator gave not enough attention to this issue via the use of full stop/period instead of the dash.

Example 8:

"The floating people were suddenly illuminated as they passed over a burning tent and Harry recognized one of them: Mr. Roberts, the campsite manager." (p. 120)

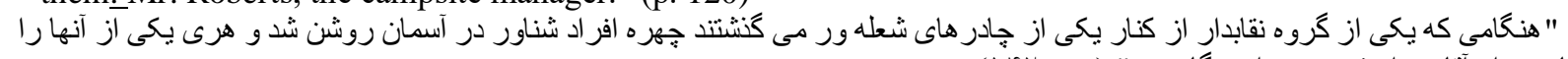

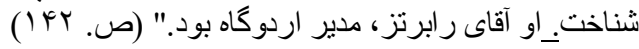

In Example 8, Eslamieh employed a full stop/period “.” instead of a colon ":” to make the meaning of the statement clear to the target readers. The main usage of the colon is to show and explain the strong and direct relationships between two components in a sentence/paragraph (the relationship between Mr. Roberts and the one who was recognized by Harry in Example 8). Doing this may be appropriate for some cases but not all.

In general, observance of grammatical and punctuations rules of any language gives the indication of validity and aesthetic of the writing, especially in the case of expressive texts. This allows the author to convey better the meaning of what he intends to the audiences. In addition, this also helps the readers to read the text fluently and understand it easily. In rare cases, her ignorance of some punctuations, such as dashes and colons, may have been done correctly because the use of such punctuations in some cases prevents the correct transmission of meaning of a statement, which leads to a decrease in the reader's understanding of that statement.

The stylistic elements, as Reiss (2000) implies, the complete correspondence between the ST and TT that needs to be taken into consideration by the critic when criticizing a translation. Thus, the main focus should be on "whether the translation gives due consideration to the differences between colloquial and standard or formal usage observed in the original" (p. 64). As the results indicate, the rhythmic tone applied by JK Rowling in her writing via the use of "-ing" that this type of style was observed in the Persian translation (see Example 9).

Example 9:

"They were soon caught up in the crowds now flooding out of the stadium and back to their campsites. Raucous singing was borne toward them on the night air as they retraced their steps along the lantern-lit path, and leprechauns kept shooting over their heads, cackling and waving their lanterns." (p. 117)

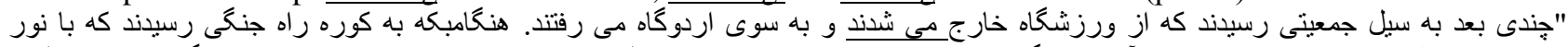

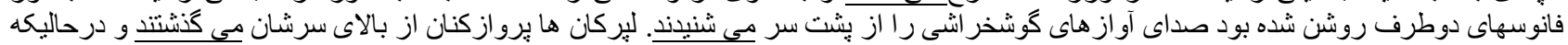

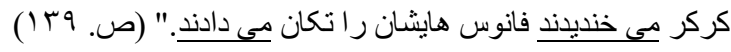

\section{Pragmatic Category}

Pragmatic category is the last level of Reiss's (2000) trancism approach in which the extra-linguistic determinants should be considered from which the first is the immediate situation. This factor includes "expressions are found very frequently in the volatile dialogues of plays and novels" (p. 69). Such texts, as she argues, pose major challenges to the translator in such a way that he should imagine himself in the situation of the speaker. This allows the translator to find an appropriate TT equivalent for the ST item to help the target readers to have better understanding of both the words and their context. The performance of Eslamieh in such situations was mainly acceptable. She enabled the target readers to understand the ST items easily via the use of optimal TT equivalent (for example see example 4).

The subject matter is the next factor that refers to "the translator be sufficiently familiar with its field to be able to construct a lexically adequate version in the target language" (p. 70). This factor is of great importance in the translation of technical texts. As the present study investigated the expressive text type, this factor was not the main concern.

In the case of the time factor, there was no difference between the ST and TT in terms of publication time because the ST was published in 2000 and the TT was made in 2002, two years later. Thus, the novel was not an old English and taken into account as one of the best novel in its own time. In addition, the translation was made by the use of modern Persian. The second component of extra-linguistic determinations is the place factor. The novel was written in the context of England with fictional places and wizarding characters that encompassed various references to such places 
and characters which can mainly decrease the understanding of the target readers of the text. The translator should do his best to present the esthetic values of the ST into the TT that Eslamieh did this to great extent. The third is audience factor. The central audiences of Harry Potter and the Goblet of Fire are teenagers. The same age-range also belong to the audiences of the novel in Iran. Hence, this factor plays the main role in choosing translation strategies by the translator. The last extra-linguistic determination is the speaker factor that refers to the language of the author. The speaker of this novel is J.K. Rowling whose novel includes many unique structures. This is the translator who decides to retain her style and the novel's structure in the translation via the use of translation strategies. Eslamieh almost preserved the author's style at different levels (see Section 4.2). The last factor is the affective implications that not only, as Reiss discusses, affect primarily lexical and stylistic matters, but also extend to the grammatical level of the SL (see the analysis of grammatical and lexical elements in Section 4.2).

The results of the study conducted by Tezcan (2015) had some similarities to the results obtained from this study. In his study, many different trancism approaches were applied to different text types proposed by Reiss's (2000), one of which was Reiss's approach. He reached the conclusion that there is not an acceptable trancism approach to be used for all text types. Moreover, Reiss's approach, as he mentions, was mainly applicable to expressive text types rather that informative and appellative types.

\section{CONCLUSION}

Trancism aimed to judge a translated text systematically on the basis of an objective criterion not on personal bias. This led to emergence of different trancism approaches proposed to be applied by reviewers/critics in order to achieve a faire critique with the aim of improving the translator's production not of making the work worthless. It should be claimed that there is no a unique and an accepted approach/model to be used for the critique of all text types. In this relation, Valero (1995) reminds us that "each text type is in need of "different methods of translation criticism in order to assess its quality" (p. 210). The present study examined the appropriateness of Reiss's (2000) approach to trancism by making a judgment on the Persian translation of J.K. Rowling's Harry Potter and the Goblet of Fire. According to the results derived from the analysis, the translator had much success in translating the ST at almost all levels of Reiss's model, including literary, language, and pragmatic levels. The main failure of the translator was in some parts relating to punctuations, a sub-level of language level. In conclusion, Reiss's functionalist-oriented approach was mostly appropriate for the critique of expressive text types, because her approach takes into account not only linguistic but also extra-linguistic determinations.

\section{REFERENCES}

[1] Baker, M. (1993). Corpus linguistics and translation studies: Implications and applications. In M. Baker, G. Francism \& E. Tognini-Bonelli (Eds.), In text and technology: In honor of John Sinclair (pp. 233-250). Amsterdam: John Benjamins.

[2] Creepy (2021). In Cambridge advanced learner's dictionary (3rd ed.). Cambridge: Cambridge University Press.

[3] Hatim, B. (1999, March 24). The cultural and the textual in the way translation studies has evolved. Paper Presented at The University of Salford, UK, ESRI Research Seminars.

[4] Hewson, L. (2011). An Approach to translation criticism: Emma and Madame Bovary in translation. Amsterdam: John Benjamins Publishing Company.

[5] Holmes, J. S. (1972) The name and nature of translation studies. In L. Venuti (Ed.), The translation studies reader (pp. 172185). London: Routledge.

[6] Kreiner, C. (2006). Translation criticism and unknown source texts. Perspectives: Studies in Translatology, 13(4), $278-288$.

[7] Newmark, P. (1998). A textbook of translation. New York: Prentice Hall.

[8] Reiss, K. (2000). Translation criticism- the potentials \& limitations: Categories and criteria for translation quality assessment (E. F. Rhodes, Trans.) Manchester: St. Jerome Publishing. (Original work published 1971).

[9] Rowling, J. K. (2000). Harry Potter and the goblet of fire. London: Bloomsbury Publishing Company.

[10] Rowling, J. K. (2002). Harry Potter and the goblet of fire (V. Eslamieh, Trans.). Tehran: Tandis Publication. (Original work published 2000).

[11] Schulte, R. (2019). Translation criticism. Retrieved from https://www.utdallas.edu/research/cts/ essays/ criticism _ essay1.html (accessed 28/10/2020).

[12] Tezcan, T. (2015). Applicability of translation criticism approaches to different text types (master's thesis, Hacettepe University Graduate School of Social Sciences). Retrieved from https://www.openaccess.hacettepe.edu.tr > bitstream > handle (accessed 09/10/2020).

[13] Toury, G. (2012). Descriptive Translation Studies - and beyond. Amsterdam: John Benjamins Publishing Company.

[14] Valero, C. (1995). Translation criticism as an independent area of study: Developing a framework for objective criticism. Livius, 7, 201-212. 


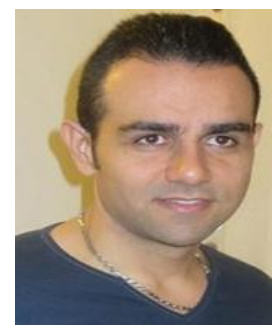

Hamidreza Abdi holds a master's degree in Translation Studies from Azad University, Science and Research, Tehran, Iran in 2016. He received his B.A. in the same major from Azad University, Roodehen, Iran in 2009.

$\mathrm{He}$ is a freelance researcher in the field of Translation Studies. He has also published numerous articles in different areas of translation. His main interest is research in translation and technology. 